\title{
Limiting the risk of injury through safety guidelines in a physical education setting
}

\author{
Andrew Fitzgerald ${ }^{1}$ \\ Joe Deutsch ${ }^{2}$
}

\begin{abstract}
Physical activity involves risk and thus the physical education classroom requires safety standards to be established and maintained to ensure safety. The number of physical education related injuries in elementary, middle school, and high school increased 150\% from 1997 to 2007 and they have continued to rise in the last decade as well. The classroom teacher must employ the highest level of organization and management in order to limit their risk. Working together with administration to establish policy and review safety standards ensures that multiple entities are involved in ensuring safety. Having safety guidelines within a physical education setting could potentially help protect the students from unnecessary injuries and may prevent the school district from legal action in the case of an injury.
\end{abstract}

Keywords: Physical Education; Safety Guidelines; Risk; Liability; Management.

\section{Introduction}

All physical activity brings some element of risk. This is not any different in a physical education setting. Therefore, when there are groups of students engaging in fitness activities, lifting weights, or playing games, the physical nature of each activity will have varying degrees of risk for injury. Indeed, the overall safety of the students should be a priority for all staff members. It is up to the school administration and teachers to make sure that there is a set standard of practice to reduce frequency and severity of injury. These safety guidelines should be clear, precise, and regularly reviewed by school staff to make sure that they are up to date with current teaching practices. Current research suggests, "Safety guidelines, if properly used, can reduce the risk of legal action against school district personnel and provide community stakeholders information about school safety" (Rothe, 2009). It is of utmost importance that physical education teachers do everything in their power to prevent injuries from occurring within their classes.

\section{Risk of Injury}

A study conducted by the Center for Injury Research and Policy of The Research Institute at Nationwide Children's Hospital (Nelson, Alhajj, Yard, Comstock, \& McKenzie, 2009), finds that the number of physical education related injuries to elementary, middle, and high school students in the United States increased 150 percent between 1997 and 2007. They report that the most common injuries were sprains, strains, and fractures. Furthermore, middle school students had the highest overall injury rate and elementary school students had the highest rate of head injuries. In fact, six activities account for most of the injuries: running, basketball, football, volleyball, soccer, and gymnastics (Nelson et al, 2009). It is important that teachers know statistics such as these

\footnotetext{
${ }^{1}$ M.S., North Dakota State University, Graduate Assistant, HNES, andrew.fitzgerald@ndsu.edu

2 Ph.D., North Dakota State University, Associate Professor, HNES, joe.deutsch@ndsu.edu.
} 
Fitzgerald, A., \& Deutsch, J. (2016). Limiting the risk of injury through safety guidelines in a physical education setting. Journal of Human Sciences, 13(2), 2856-2859. doi:10.14687/jhs.v13i2.3783

before beginning an activity. The fact that certain activities bring a greater risk of injury highlights the need for instructors to spend extra time in order to ensure safety guidelines are properly understood and followed. Activities with a higher injury risk, such as tug of war or rope climbing, which could lead to rope burns, could be modified to reduce the risk of injury (Williams, 2015). Moreover, it is important to look at possible modifications rather than discarding the activity altogether. For example, the activity could be changed or modified to be safer and more inclusive for all students. More specifically, a game of dodgeball could be modified so that an object is a target rather than a student. "This allows students to work on the same skills they did in the original dodgeball game, but eliminates attempting to strike another student" (Deutsch, 2007, p.49). Having the foresight to modify an activity before an injury occurs is a skill that teachers can develop over time.

In addition to modifying activities, they must also be differentiated to meet the specific needs and abilities of the students to ensure safety. For example, lifting a forty-five pound Olympic bar may be easy for one student, but extremely difficult for others in the same class, thus increasing the possibility of injury. A twenty-five pound bar or dumbbells should be substituted in such cases. This allows for a more inclusive environment in which the students are not limited by their ability. Students may grow stronger and gain confidence as the year progresses, and be able to advance to the heavier weight.

\section{Structure and Organization}

While considering the varying abilities of the students, it is important that activities throughout the school year be structured to minimize the potential risk of injury. This includes adequate warm-up, proper footwear, and knowledge of the rules to help reduce common injuries (Ellenberger \& Deutsch, 2014). Early in the school year, activities should focus on simple movements such as stretching and balancing. The most common injuries in Physical Education classes are sprained ankles; and using balance training will help reduce these incidences (McHugh, et al., 2007). Dress code policies should emphasize athletic shoes, and not allow a student to wear sandals, boots, or any other type of shoe not suited for physical activity. A teacher cannot assume that every student is prepared for a game with sprinting and sudden movement changes such as soccer or basketball. At the beginning of a semester, abilities must be assessed so the students can be placed in appropriate activities. This can be done through programs such as Fitnessgram to test areas such as strength, endurance, and flexibility.

Class size is also an important factor when considering student safety. A class size that is not too large "ensures that the number of students allows the teacher to be effective in teaching and supervising the students" (Murphy \& Beh, 2014). Large class sizes make supervision more difficult; this may prevent the teacher from anticipating any scenarios that could lead to student injury. In a physical education setting, classes are often spread out over a large area, and proper supervision can be challenging for a teacher when dealing with a lot of students. If a teacher is faced with the challenge of a large class, planning must be done prior to each activity to ensure adequate supervision.

\section{Educate Yourself}

Equally important to activities and class size, proper knowledge of the equipment as well as facility maintenance should be brought to the attention of the teachers, students, and maintenance staff. Activities that require more equipment and set-up, such as volleyball or gymnastics, must have proper instruction as how to correctly assemble and safely use each piece of equipment for teachers as well as students. Facilities must also be considered, and having basic safety measures such as padding on the walls and on any sharp corners is essential. Outdoor playing surfaces should be properly maintained and free of holes, rocks, and uneven terrain. Other high-risk areas, such as weight rooms and swimming pools, should have visible safety guidelines posted in high traffic areas. Equipment used for each activity should be inventoried and inspected, while removing or 
Fitzgerald, A., \& Deutsch, J. (2016). Limiting the risk of injury through safety guidelines in a physical education setting. Journal of Human Sciences, 13(2), 2856-2859. doi:10.14687/jhs.v13i2.3783

repairing any equipment that could pose an injury risk. Next, a facility walk-though should be completed, with staff members observing and recording any areas of concern. During this process, specific problem areas can be pointed out to the building principal.

A facility analysis should be done prior to the end of the school year so there is adequate time for maintenance staff to make any needed repairs or adjustments to the facilities. This will also allow ample time to place orders for equipment that needs to be repaired or replaced. Money should be budgeted on a yearly basis to address safety needs. If an expensive piece of equipment, such as a treadmill, cannot be properly repaired because of lack of funding, it should be deemed unusable until it is either repaired or replaced. Areas such as the swimming pool, fitness room, and gymnasium should have properly working locks on the doors so the area is inaccessible when not in use. Any facility hazards such as faulty locks must be prioritized and repaired immediately. Building malfunctions such as leaky roofs that could cause slippery floors should also be repaired upon discovery.

\section{Safety Guidelines}

Safety guidelines should be prepared by teachers and reviewed by administration. These two groups can work together to assess risk factors and determine proper action for each. A review of current safety practices by the teachers will set the basis for the guidelines. From there, they can analyze each practice and decide to leave it as is, add to it, or remove it altogether. Once this is accomplished, the teachers and administration can determine what areas need to be addressed and create guidelines to meet these areas. During this process, each component of the curriculum should be reviewed, with potential safety concerns of each activity discussed.

Furthermore, it is important that department members be properly trained in each area of the curriculum. This may be done through professional development, staff meetings, literature review, and peer to peer communication. New staff members need to be educated on current safety practices within each area of the building and with the instruction of each activity. Staff should be required to be certified in CPR/AED and First Aid (Sawyer \& Gimbert, 2014). This includes periodic checks to ensure that certifications are current.

Once guidelines are in place and all staff has been trained, it is important that there are checks incorporated to make sure they are being followed. Individual staff members should include safety procedures in daily and weekly lesson plans. This encourages them to make safety a habit, and help teachers consider possible hazards within each activity. It is important that the guidelines be specific to each activity so a teacher can do a short review before each unit. A copy of the department safety policy should be made available for substitute and student teachers to review. It is important that the policy be clear, concise, and easily accessible. Some teachers find it laborious to meet all of the guidelines when they are oversaturated with policies, regulations, and guidelines (Rothe, 2009). This emphasizes the point that guidelines need to be condensed, and able to be used as a quick reference for the teacher.

Additionally, safety procedures and concerns should be noted during peer observations. These peer observations may be done formally or informally; and immediate feedback is essential when a safety hazard is observed. Consistent dialogue regarding safety between members of the physical education department is critical. Safety should be an ongoing agenda item during department meetings so it is not overlooked. Peer observations from outside the department could prove to be beneficial as well; someone who is not familiar with daily physical education activities may bring a different perspective and see potential problems from an alternate point of view. Moreover, during the administrative observation and evaluation process, building principals should note any potential problem areas and address any liability concerns that are observed.

Regular review of the guidelines is important, and this would best be done towards the end of the school year. All department members should be included, regardless of age or experience. Any injuries that occur should be logged, and during an annual review the injuries should be analyzed to see if there are any commonalities among the types of injuries or activities. The injury 
Fitzgerald, A., \& Deutsch, J. (2016). Limiting the risk of injury through safety guidelines in a physical education setting. Journal of Human Sciences, 13(2), 2856-2859. doi:10.14687/jhs.v13i2.3783

$\log$ should be as specific as possible, providing a short but detailed report of the type of injury, how it happened, and if anything could have been done to prevent it. The results of the compiled data could be used to enhance the safety of both the facilities and the mode of instruction (Luce \& Deutsch, 2014). The guidelines may also need to be adjusted to meet any changes in curriculum for the upcoming school year. Any potential safety hazards should be addressed at this time, and there can be staff discussion on whether any policy changes need to happen. If injuries are occurring at an unusually high rate, this meeting may need to happen mid-year in order to help prevent future problems. It is important that all department members prioritize safety, even those with many years of experience. More experienced teachers are less likely to review safety guidelines than younger teachers, feeling that they have been doing their job long enough to be able to assess potential safety risks (Rothe, 2009). Having the more experienced teachers be in a leadership position when it comes to safety may help prevent this.

\section{Conclusion}

Having safety guidelines within a physical education setting could potentially help protect the students from unnecessary injuries, and may prevent the school district from legal action in the case of an injury (Christianson, Breker, \& Deutsch, 2012). If safety procedures are put at the forefront of a physical education program, teachers may be more aware of and anticipate any problem areas. Having checks and balances within the system may increase compliance and place importance on safety for all students. It is up to the physical education teachers to develop and put these ideas into practice to minimize, and ideally prevent any potential risk to their students.

\section{References}

Christianson, N., Breker, M., \& Deutsch, J. (2012). How to run a soccer camp: For adolescents (Age 6-14), Journal of Youth Sports, 7(1), 13-18.

Deutsch, J. (2007). From hall of shame to hall of fame: Transforming traditional elementary activities. Missouri Journal of Health, Physical Education, Recreation, and Dance, 17, 48-52.

Ellenberger, R. \& Deutsch, J. (2014). How to run a football camp: For adolescents $\left(9^{\text {th }}-12^{\text {th }}\right.$ grade), Journal of Youth Sports, 7(2), 9-19.

Luce, K. \& Deutsch, J. (2014). How to run an academy season for youth soccer, Journal of Youth Sports, 7(2), 24-27.

McHugh, M., Tyler, T., Mirabella, M., Mullaney, M., and Nicholas, S. (2007). The effectiveness of a balance training intervention in reducing the incidence of noncontact ankle sprains in high school football players, American Journal of Sports Medicine, 35(8), 1289-1294.

Murphy, K. \& Beh, H. (2014). The standard of care and the assumption of risk defense in a negligent injury case in a physical education class, Journal of Physical Education, Recreation, \& Dance, 85(8), 41-43.

Nelson, N., Alhajj, M., Yard, E., Comstock, D., and McKenzie, L. (2009). Physical education class injuries treated in emergency departments in the US in 1997-2007. Pediatrics Sept. 2009: $918+$.

Rothe, P. (2009). The voluntary use of physical education safety guidelines in schools, Journal of Physical Education, Recreation \& Dance, 80(3), 43-49

Sawyer, T. \& Gimbert, T. (2014) Lack of safety equipment, Journal of Physical Education, Recreation, \& Dance, 85(3), 50-51.

Williams, N. (2015). The physical education hall of shame, Part IV: more inappropriate games, activities, and practices, Journal of Physical Education, Recreation, \& Dance, 86(1), 36-39. 